NUTRITION AND

CARDIOVASCULAR

DISEASE

\title{
Cardiovascular disease and nutrition: The use of food-based dietary guidelines for prevention in Africa
}

\section{P.T. Pisa", H.H. Vorster ${ }^{*}$ and C. Nishida"}

*Centre of Excellence for Nutrition, North-West University,

Potchefstroom, South Africa

\#World Health Organisation, Geneva, Switzerland

Address for correspondence:

Dr P.T. Pisa

Centre of Excellence for Nutrition

North-West University

Private Bag X600 I

Potchefstroom

2520

South Africa

Email:

20369190@nwu.ac.za / pppedropissa@gmail.com

\section{INTRODUCTION: CARDIOVASCULAR DISEASE (CVD) IN AFRICA}

The global burden of CVD is enormous and is rapidly escalating in developing countries.(1) At present, this burden seems to be the second major public health concern after HIVIAIDS in many developing countries. The World Health Organisation (WHO) estimated in 2002 that $29 \%$ of deaths worldwide were due to CVD, and that $43 \%$ of global morbidity and mortality, measured in disability-adjusted life years (DALYs), was caused by CVD. ${ }^{(2)}$ It is estimated that by 2020, CVD will be the leading cause of death, probably accounting for $73 \%$ of total global mortality and $56 \%$ of morbidity. ${ }^{(3,4)}$ Africa, like many other developing regions, has traditionally focused on controlling infectious diseases. However, a health transition associated with development, urbanisation and modernisation of dietary patterns and lifestyles has contributed hugely to an increase in non-communicable diseases (NCDs), to the extent that in $200 \mathrm{I}$, already $20 \%$ of deaths in sub-Saharan Africa were because of NCDs. ${ }^{(1)}$ Clearly, a new approach to disease prevention in these countries is needed.

\section{ABSTRACT}

There is no doubt that morbidity and mortality from cardiovascular disease (CVD) are increasing in many African countries. Research and implementation of public health nutrition programmes in the developed world have shown that CVD can be prevented by dietary interventions. The objectives of this paper are to (i) review the relationships between diet and CVD; (ii) review the possible contribution of the nutrition transition, which is associated with economic development and "modernisation" to CVD in Africa; (iii) identify barriers and challenges plus assessing the opportunities available to steer the nutrition transition into a more positive direction; and (iv) show how ideal nutrient intakes can be translated into appropriate food based dietary guidelines (FBDGs) and how to apply these for prevention and management of CVDs. This should result in appropriate recommendations for diets that will be country-specific, affordable, culturally acceptable and based on available, traditional and indigenous foods. It is concluded that all health professionals should be sensitised, informed, trained and/or educated to apply FBDGs in a way that will motivate the public or patients to follow healthier diets for primary, secondary and tertiary prevention and treatment of CVD. SAHeart 20। I; 8:38-47

CVD the second major cause of death in Africa, accounting for almost I I\% of total deaths. ${ }^{(5)}$ The burden of CVD faced by African countries is most likely to double by 2020 , due the accelerated pace of transition. In a prospective study among patients in Kenya, clinical evidence of CVD was present in $40 \%$ of the patients evaluated: over $52 \%$ were hypertensive and had arrhythmia, and $49 \%$ had congestive cardiac failure. ${ }^{(6)}$ In a Cameroonian study from 1992-1997, coronary artery disease was ranked eighth among CVD with a prevalence of $1.53 \% .^{(7)}$ The same study showed a high prevalence of CVD risk factors such as obesity (40\%), hypertension (60\%), dyslipidaemia (43\%), smoking (36\%), diabetes/ hyperglycaemia (26\%) and hyperuricaemia (20\%). At least three of the CVD risk factors were present in $76 \%$ of the patients. ${ }^{(7)}$ In a retrospective study conducted in the same country in 1995, comprising 312 adult patients with CVD, 38.5\% were hypertensive, 
25.6\% had rheumatic valvular heart diseases and $22.5 \%$ had cardiomyopathies. $^{(8)}$ A prospective study in Ghana conducted between 1992 and 1995, revealed a high prevalence of CVD in the study population such as hypertension (18.7\%), idiopathic cardiomyopathy (17.4\%), congenital heart disease (14.5\%) and coronary artery disease (12.7), respectively, all major causes of CVD morbidity. ${ }^{(9)}$ In Mauritius between 1990 and 1994, age standardised stroke mortality between the ages of 35 and 74 years were 268 for men and 138 for women per 100 000,(10) Ghanem and Freji, ${ }^{(1)}$ estimated that in a Tunisian population prevalence of risk factors for CVD were 19\%, 10\%, 28\%, 36\% and $21 \%$ for hypertension, diabetes, obesity, android obesity and smoking respectively. In South Africa, the Heart of Soweto study ${ }^{(12)}$ indicated a very high prevalence of CVD risk factors and provided "strong evidence that the epidemiological transition in South Africa has broadened the complexity and spectrum of heart disease in the community". Clearly, this summarised data does not augur well for Africa with projections that health will not improve and neither will the level of social and economic development, unless this CVD burden is controlled.

Evidence exists from Western industrialised communities that with ideal programmes and strategies, CVD and its risk factors can be reduced and are preventable.(13-16) The decline in coronary mortality in Finland ${ }^{(17)}$ is often used as an example of how it is possible to control CVD. A holistic, community-based cardiovascular control programme, which included a variety of measures to change dietary intakes, was initiated in 1972 in North Karelia, a county in the Eastern part of Finland. The decline in coronary mortality in this region between 1969 and 1979 was 24\% in men and $51 \%$ in women. The drop in the rest of Finland over the same period was $12 \%$ in men and $24 \%$ in women. The decline in North Karelia was greater than that of other counties of Finland for both men and women, suggesting that the preventive programme was effective. (17) Nutrition/diet has been shown to be a significant modifiable independent risk factor for CVD. $(18,19,20,21)$

Despite this knowledge of prevention of CVD, one should pose the question: why does Africa, together with other developing regions, continue to experience an uncontrollable increase in mortality and morbidity due to CVD? We propose that changes in lifestyle, especially changes from traditional prudent dietary patterns and nutrient intakes to modern, imprudent diets, play a major role. Therefore, in the rest of this paper, we will focus on the relationships between nutrition and CVD risk; the present nutrition transition in Africa; the barriers, challenges and opportunities available to reduce the dietary risk of CVD in Africa, and especially how appropriate food based dietary guidelines (FBDGs) for specific groups of people can be applied for prevention and management of CVD.

\section{THE RELATIONSHIPS BETWEEN NUTRIENT}

\section{INTAKES AND CVD}

The evidence that optimal, prudent and adequate nutrient intakes can reduce CVD risk is convincing. (19,20,22,23-25,26) An imprudent diet; high in saturated fats, ${ }^{(27,28-32)}$ salt, ${ }^{(33)}$ alcohol, ${ }^{(34,35)}$ and refined carbohydrates, ${ }^{(36)}$ low in fruits and vegetables ${ }^{(37)}$ and with more energy than needed, is strongly associated with increased risk for developing CVD. ${ }^{(19)}$ The link of this diet with CVD risk factors is illustrated in Figure 1 .

The ideal prudent but adequate (balanced) nutrient profile agreed by national, regional and international bodies ${ }^{(38-40)}$ that establish dietary requirements for the prevention of diet-related NCDs, including CVD, are summarised in Table I. It is important to realise that the optimal nutrient profile to prevent and treat CVD given in Table I, can be accomplished by many different food combinations, which may for example result in the Mediterranean diet, a typical traditional African diet, or others.

The Table emphasises that for prevention of CVD, diets must have sufficient amounts of fruits, vegetables and whole-grain cereals but limited amounts of energy, saturated and trans fatty acids, added sugars, refined carbohydrate sources, salt and alcohol.

\section{FATS AND OILS}

A diet with excess saturated and trans fats leads to dyslipidaemia, and especially hypercholesterolaemia a risk factor for CVD. . $^{(1,23-25,41)}$ Saturated fats are mostly found in animal products. Trans fats are found in semi-hard oils that have undergone hydrogenation in 
Relationships between nutrition and non communicable diseases
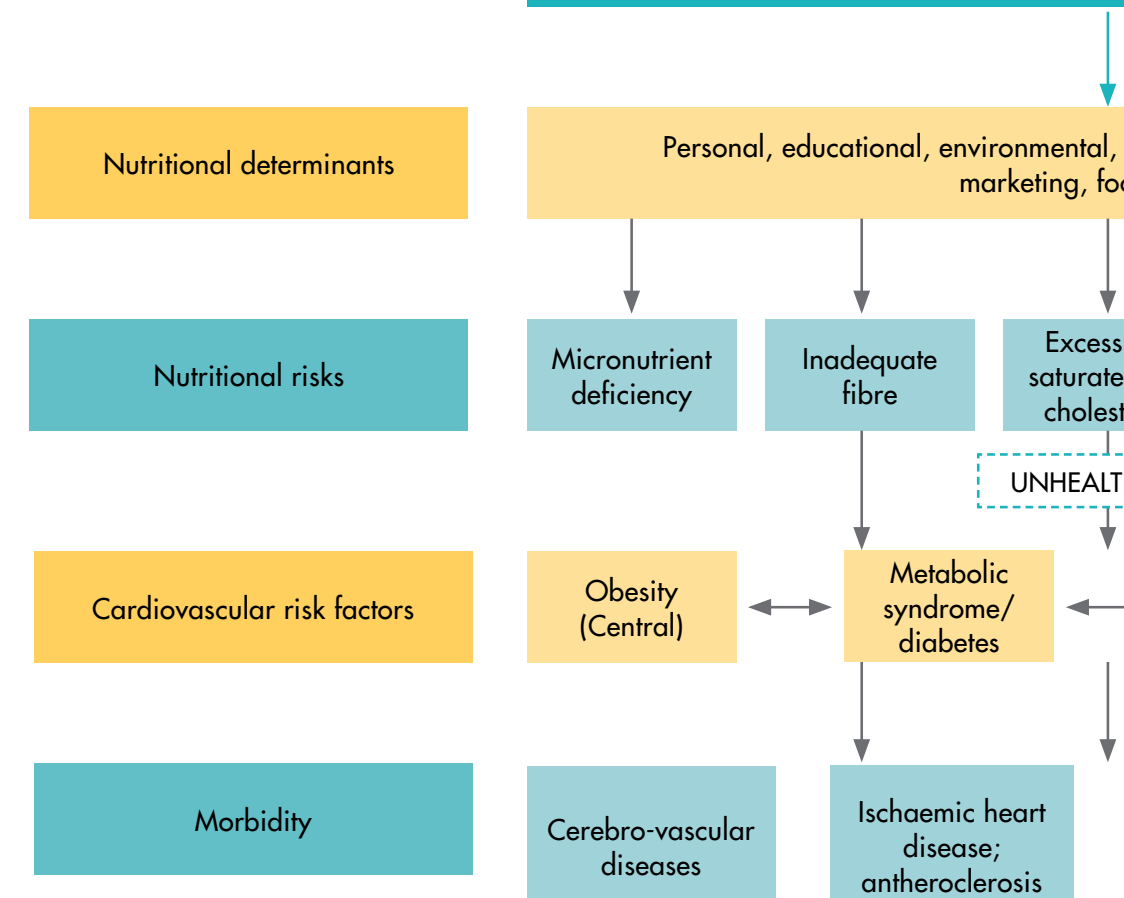

Personal, educational, environmental, economic, commercial, advertising, marketing, food labeling

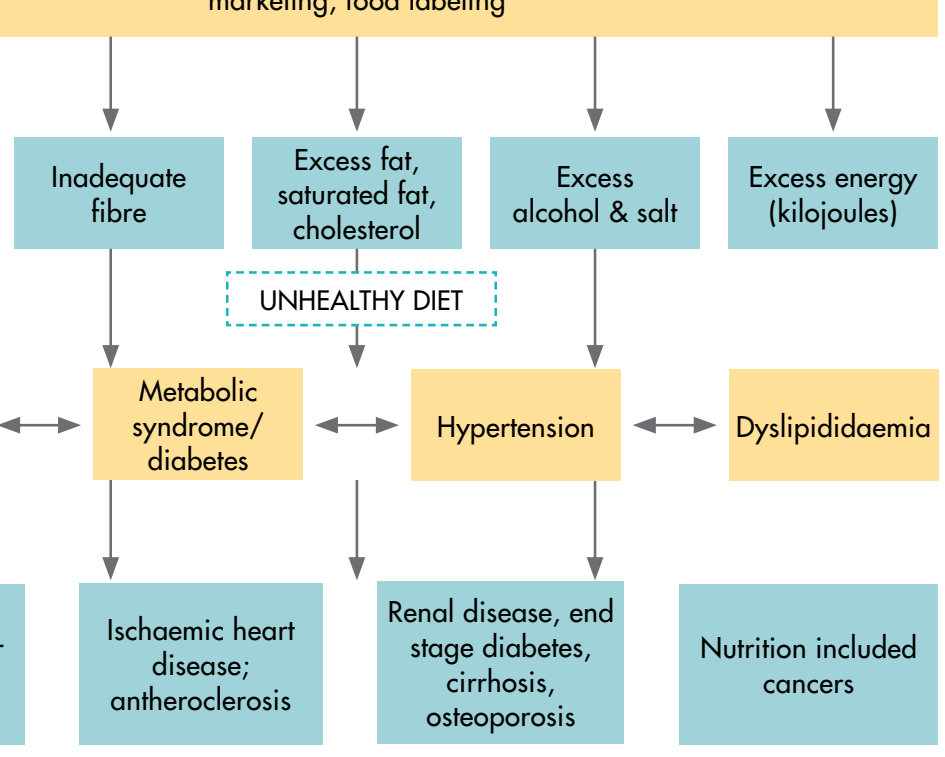

STROKE

\section{MYOCARDIAL}

INFARCTION

the manufacturing of margarines. The new inter-esterification process that replaced hydrogenation gives margarine less trans fats. Saturated fats should be replaced by poly- and monounsaturated oils, shown to be beneficial for overall cardiovascular function and health. ${ }^{(20,21,23-25)}$ The major sources of these oils are plant food sources such as soybean, sunflower, rapeseed, palm and groundnut oil. The essential omega 3 and omega 6 fatty acids are mainly found in fish oils, ${ }^{(42-45)}$ nuts, ${ }^{(46-49,50)}$ soy bean oil, ${ }^{(51)}$ and are additionally preventative of CVD. (18,19,20,21) Additionally plant sterols have been shown to reduce CVD in different populations. ${ }^{(52,53,54)}$

\section{“FREE” OR ADDED SUGARS}

High intakes of mono- and disaccharides added to foods and drinks may reduce or dilute nutrient quality of diets by providing only energy, therefore contributing to overall energy density, a low micronutrient density, a positive energy balance, and increased weight gain. A randomised trial showed that when soft drinks rich in free sugars are consumed there is a higher energy intake and a progressive increase in body weight when compared to situations in which energy-free drinks that are artificially sweetened are consumed. ${ }^{(55)}$ The recommendation is that to prevent these effects, not more than 10\% of total energy intake should be in the form of added sugars. ${ }^{(56)}$

\section{MICRONUTRIENTS AND DIETARY FIBRE}

Essential vitamins, minerals, dietary fibre (non-starch polysaccharides, or NSP), phytosterols and various anti-oxidant phytochemicals, all play, through a variety of mechanisms, a pivotal role in the 
prevention and management of CVD and other NCDs. ${ }^{(57-60)}$ The benefit of fruit, vegetables, legumes and whole-grain cereals, all dietary sources of these nutrients, is undisputable. (20) Low intakes of fruit and vegetables account for $20 \%$ of CVD worldwide. ${ }^{(61)}$ The present recommendation is that at least five servings (400 - 500 grams) of fresh fruit and vegetables, and cereals and grains in unrefined form where possible should be eaten daily.

\section{TABLE SALT AND ALCOHOL}

A diet high in salt or sodium chloride increases the risk of developing hypertension in susceptible persons, a major risk factor for CVD. ${ }^{(33)}$ A universal reduction of about $3 g$ of salt a day, could lead to a

TABLE I: Ranges of population nutrient intake goals for prevention of NCDs.(38-40

\begin{tabular}{|l|c|}
\hline Nutrient & $\begin{array}{c}\text { Goal (\% of total energy, unless } \\
\text { otherwise stated) }\end{array}$ \\
\hline Total fat & $15-30 \%$ \\
\hline Saturated fatty acid (SATFAs) & $<10 \%$ \\
\hline Polyunsaturated fatty acids (PUFAs) & $6-10 \%$ \\
\hline n-6 PUFAs & $5-8 \%$ \\
\hline n-3 PUFAs & $1-2 \%$ \\
\hline Trans fatty acids & $<1 \%$ \\
\hline Monounsaturated fatty acids (MUFAs) & By difference \\
\hline Total carbohydrate & $55-75 \%^{*}$ \\
\hline Free sugars & $<10 \%$ \\
\hline Protein & $10-15 \%{ }^{* *}$ \\
\hline Cholesterol & $<300 m g$ per day \\
\hline Sodium chloride (sodium) ${ }^{\#}$ & $<5 g$ per day $(<2 g$ per day) \\
\hline Fruits and vegetables & $\geq 400 \mathrm{~g}$ per day \\
\hline Total dietary fibre & From foods ${ }^{*}$ \\
\hline Non-starch polysaccharides (NSP) & From foods ${ }^{*}$ \\
\hline Col & \\
\hline
\end{tabular}

"Calculated as: total fat - (saturated + polyunsaturated + trans fatty acids).

¥The percentage of total energy available after taking into account that consumed as protein and fat, hence the wide range.

\$The term "free sugars" refers to all monosaccharide and disaccharides added to foods by the manufacturer, cook or consumer, plus sugars naturally present in honey, syrups and fruit juices.

"*The suggested range should be seen in the light of the Joint WHOIFAOIUNU Expert Consultation on Protein and Amino Acid Requirements in Human Nutrition, held in Geneva in April 2002.(38)

\#Salt should be iodised appropriately. The need to adjust salt iodisation, depending on observed sodium intake and surveillance of iodine status of the population, should be recognised.

¥The recommended intake of fruits and vegetables and consumption of wholegrain foods is likely to provide $>20 \mathrm{~g}$ per day of NSP ( $>25 \mathrm{~g}$ per day of total dietary fibre).
$50 \%$ reduction in the number of people needing treatment for hypertension, a $22 \%$ drop in the number of deaths resulting from strokes and a 16\% fall in the number of deaths from coronary heart disease. ${ }^{(61)}$ There is a hypothesis that African populations have a genetic predisposition for salt retention, which may be compounded in urban African cultures where salt intakes are generally high, causing an increased prevalence of hypertension. ${ }^{(62)}$

Epidemiological evidence suggests a J or $U$ shaped relationship between alcohol consumption and CVD, ${ }^{(34,35,63)}$ which resulted in an acceptance that moderate consumption of alcoholic beverages such as red wine, may be cardio-protective. However, in a population-based study amongst 2010 black South Africans, increased alcohol consumption was associated with favourable lipid profiles (increases in HDL-cholesterol) but also with increased blood pressure, indicating that the cardio-protective effect of alcohol possibly disappears because the increase in blood pressure offsets the benefits. ${ }^{(64)}$

\section{CHANGING DIETARY PATTERNS IN AFRICA:}

\section{THE NUTRITION TRANSITION (NT)}

The NT in Africa, which accompanies economic development, industrialisation, urbanisation and more sedentary lifestyles, is characterised by an increased intake of animal-derived foods, "fast or convenience" fried and/or packaged foods, salty and sweet snack foods, sugary and/or alcoholic beverages, while intakes of plant-derived foods such as staple whole-grain cereals, legumes, fruit and vegetables decline. ${ }^{(65,66)}$ Although some of these dietary changes may actually improve intakes of some micronutrients such as more iron from meat or calcium from milk, they mostly result in diets with too much energy, saturated and trans fats, salt, alcohol and sugars, and not sufficient dietary fibre (NSP), as well as deficiencies of many micronutrients and anti-oxidant phytochemicals. The result is an increased risk of NCDs, including CVD, which explains the observed increased morbidity and mortality from these diseases in developing countries such as South Africa. ${ }^{(67)}$ Tragically, in many developing countries, the transition to these "modern" diets is taking place before the battle against undernutrition has been won, resulting in a double burden of infectious and NCDs, further exacerbated by the HIVIAIDS pandemic. ${ }^{(65)}$ 


\section{BARRIERS AGAINST STEERING THE NT IN A} MORE POSITIVE DIRECTION

A critical question at this stage of development in Africa is why has it proven so difficult to steer the NT into a more positive direction, moving populations from undernutrition to optimal nutrition and not to overnutrition? The answer is probably because the many, integrated forces driving the NT are also barriers to optimal nutrition. These include inter alia negative changes in the food environment, inherent food preferences, lack of knowledge, and the poverty-malnutrition cycle.

The changed food environment is a consequence of globalisation and economic development leading to availability and affordability (even for many poor people) of food products such as salty and sweet snacks, fast foods, cheap fats and oils and sweetened beverages not previously easily assessable. It is especially the food industry that could play a role in this area to improve and promote the availability of healthier products at affordable prices, and governments through policies, legislation and intervention programmes to facilitate a healthier food environment.

Another barrier is that humans inherently prefer and have appetites for creamy, fatty, sweet and salty foods with a high energy density and lack of fibre. ${ }^{(68)}$ In addition to many direct effects on CVD risk factors, high intakes of these foods, coupled to more sedentary lifestyles could lead to obesity, a risk factor of CVD (and other NCDs). A lack of knowledge and support to change behaviours regarding healthy food choices are also barriers. This is often exploited by the food industry, marketing and promoting food products in ways that are not conducive to good nutrition. In children and adolescents inappropriate advertisements and peer pressure can also contribute to the wrong food choices. Governments and institutional bodies can play important roles by legislating against practices such as advertising certain products during children's television programmes in an attempt to combat childhood obesity, ${ }^{(69)}$ or for example regulating what is sold at school venues. Labelling of food products and informing consumers how to interpret labels may help to remove some of these barriers.

A major obstacle in steering the present rapid NT into a more positive direction is the difficulty of breaking the vicious inter- generational poverty-malnutrition cycle. This cycle starts when malnourished women become pregnant. It is now known that nutritional insults during foetal life may programme the foetus to be vulnerable for several NCDs in later life when exposed to an imprudent diet. This is in addition to possibly being a low-birth weight or disproportionate baby, as well as a mental and physical stunted child, developing into an adult with low human capital, unable to escape poverty and malnutrition. ${ }^{(70)}$ This phenomenon contributes to the co-existence of undernutrition in children and high prevalence of obesity and NCDs in adults that many African countries are experiencing at the moment.

\section{HOW DO WETRANSLATE THE OPTIMAL CVD-} PREVENTATIVE NUTRIENT PROFILE INTO

\section{PRACTICAL FOOD-BASED DIETARY} GUIDELINES (FBDGS)?

From the above it is logical that to sensitise, guide and help individuals to make the right dietary choices for prevention of CVD, an appropriate food environment should be available. But equally important, it is essential to equip and empower people with the knowledge of what to eat and motivate them to make the right food choices based on this knowledge.

Because people eat foods and not nutrients, the WHO/FAO(7I) started a process in 1996 to guide member countries and regions on how to prepare and use food-based dietary guidelines (FBDGs) to address nutrition-related chronic diseases. The $\mathrm{WHO}^{(72)}$ has now published a comprehensive procedural manual for the development and implementation of regional and country-specific FBDGs to promote healthy eating for the prevention of both under- and overnutrition-related disease. In this manual, the process is discussed step-by-step on how to formulate appropriate guidelines, how to develop a suitable food guide and education material for different target groups, how to field-test developed materials, as well as how to design, monitor, and evaluate a holistic implementation plan of FBDGs, which is aligned with all other nutrition programmes within countries.

The major characteristics of FBDGs to be successful in changing eating behaviour of individuals and groups are that the FBDG- 
messages should be simple, understandable, positive, affordable take existing eating patterns into account, promote indigenous and traditional foods of all cultures in society and that they are based on the scientific evidence within countries of the prevalence of nutrition-related disease. Moreover, following the FBDGs to choose a diet must always result in adequate (balanced) diets that meet all nutrient requirements.

In South Africa, a working group, representing different organisations involved in food and nutrition, developed a set of FBDGs $s^{(73)}$ that were adopted by the Department of Health (Directorate Nutrition) as the messages to communicate healthy nutrition to different target groups. These guidelines can be used for the primary prevention as well as the treatment of NCDs, including CVD. The working group developed the messages to promote traditional diets and published the scientific evidence and rationale for each. ${ }^{(73)}$ A few other African countries like Nigeria have also developed FBDGs. It is suggested that in the absence of appropriate guidelines in some countries, the South African FBDGs are suitable for use in the whole African region to prevent both undernutrition and the risk of CVD.

The way the FBDG messages are focussed, communicated, promoted and explained to individuals and groups, will depend on the level of education and characteristics of the potential users, as well as the targets to be reached. FBDGs, appropriately illustrated by a food guide such as the plate model or the food pyramid, can be a very useful tool for all health professionals to reduce dietrelated risk factors for CVD in individuals as well as on population level by using different interview and social marketing techniques. Some practical advice on the way the South African FBDGs can be communicated and explained for prevention of CVD is given in Table 2

\section{SOME CONCLUDING REMARKS}

Besides increased mortality rates, African countries face great economic challenges with the expected CVD epidemic. The costs are largely to health systems, and to the continent as a whole. For example in South Africa, 2 to 3\% of the country's gross national income, or roughly $25 \%$ of South African healthcare expenditures, was devoted to the direct treatment of CVD in 1991.(74) This situation is made worse by the fact that such a high proportion of CVD burden occurs earlier among adults of working age in developing countries. ${ }^{(75)}$

It is difficult for policy makers and health professionals in Africa to plan for prevention, as decisions are often made by politicians. The socioeconomic consequences and costs of secondary and tertiary healthcare of CVD are high. There should be more emphasis on prevention. But unfortunately, the resources devoted towards prevention of CVD are scarce. As mentioned earlier, there are many examples of holistic, multidisciplinary intervention programmes with strong evidence for significant reductions in morbidity and mortality associated with CVD, but few of these interventions have been implemented in Africa.

Therefore, in this developing region with limited resources, the challenge would be to create and implement cost-effective, multidisciplinary prevention programmes as well as sustainable infrastructure and trained personnel for care and treatment of CVD. Because of the relationships between nutrition and CVD, these programmes should aim to equip all health professionals with adequate and relevant nutrition knowledge to contribute to improved diets and nutrition quality, ensure food and nutrition security and increase physical activity. These primary practices could curb obesity, hypertension CVD, diabetes and other NCDs.

Primary and secondary prevention of CVD are possible, but it will need capacity in the form of financial and suitably trained human resources to implement timely and appropriate dietary interventions to steer the nutrition and epidemiological transition in Africa into a more positive direction.

\section{RECOMMENDATIONS}

The first recommendation is that all health professionals should be sensitised about the important role of nutrition in the prevention 
TABLE 2: The use of the South African FBDGs ${ }^{(73)}$ for prevention of CVD.

\section{FBDG-message}

Enjoy a variety of foods

Be active!

Make starchy foods the basis of most meals

Eat plenty of fruit and vegetables

Eat dry beans, split peas, lentils and soya often

Meat, chicken, fish, milk and eggs can be eaten every day

Eat fats sparingly

Use salt sparingly

Drink lots of clean safe water

If you drink alcohol, drink sensibly

Use food and drinks containing sugar sparingly and not between meals

\section{Some additional information and advice ${ }^{(37)}$}

Enjoy eating; do not feel guilty when eating; eat as large a variety of foods that is possible (affordable), and preferably not highly processed foods; eat from each food group per day if possible (explain food groups).

Thirty minutes of moderate to vigorous activity on most days can reduce CVD mortality 1.5 to 2.0 fold. Advise on ways to increase activity (walking, climbing stairs) during daily life.

When planning meals, plan around the starchy staple food such as maize porridge, rice, bread, pasta, potatoes, sump, and other staple grains and cereals, preferably in whole, unrefined, unprocessed form where possible.

At least 400-500g of fresh (or frozen) fruit (2 servings) and vegetables (3 servings) should be eaten daily. Explain cheaper options in season, how to grow own, the use of indigenous leafy green vegetables, and that diabetics should focus more on vegetables and less on fruit. Limit additions of salt, sugar and fat and explain cooking methods that will preserve micronutrients.

Legumes are rich sources of many nutrients and dietary fibre that helps to control blood lipids and glucose. For prevention of CVD, advise on 3 servings per week and for treatment one serving per day. A serving is $100 \mathrm{~g}$ cooked legume. Tinned products are good but may contain too much salt. Best to cook own and serve as such, in salads, soups or mixed with starchy foods such as sump or bread.

One serving of an animal-derived food per day is recommended ( $100 \mathrm{~g}$ cooked meat, chicken or fish, or 2 eggs), preferably low fat options and cooked with little added fat and salt. Adults should also have $500 \mathrm{ml}$ milk or equivalent products daily, preferably the low-fat options. At least 3 fish dishes (servings) per week are advised to lower CVD risk factors.

At present it is recommended to have 15-30\% of total energy as fat, of which not more than a third should come from saturated (hard, animal) fats. To keep fat and oil intakes at this level, low-fat options of meat, and chicken without skin should be chosen as well as preparation methods with limited use of oils.

Too much salt intake is linked with hypertension. It is difficult to keep salt intake low in diets with many processed foods. Advise people to use fresh herbs and spices to flavour food and not to put salt on the table. Make sure that all salt used is iodised.

Approximately 2 litres of fluids are needed daily, preferably as clean water and not too much sugary or other drink. Relevant advice on how to sterilise water, especially in rural areas, could be given.

This guideline takes the reality that there will always be people who drink alcoholic beverages into account. It does not promote drinking, but emphasise moderate drinking which means not more than 14 tots for men and 7 for women per week. The negative health and social consequences of binge drinking and over-consumption should be explained to target groups.

This guideline is mainly aimed at dental health but individuals and groups should be made aware that over-consumption of especially sugary drinks may contribute to obesity and risk of other NCDs. 
as well as treatment of CVD. Many of these professionals have more access to individual patients and groups within communities than the relatively few trained nutritionists and dieticians.

The second recommendation is that either country-specific or regional FBDGs for Africa should be developed with different options of traditional and indigenous foods. These guidelines should be accompanied by the development and funding of appropriate marketing/training materials (at all levels: for the general population and high risk groups such as pregnant women, pre-school, and primary school children, adolescents, and the elderly), as well as plans on how to implement a holistic FBDG programme aligned with other public health interventions in a country.

The third recommendation is that all health professionals should be trained on how to implement these FBDGs to prevent and treat CVD, as well as other nutrient-deficiency and non-communicable diseases. Nutrition should form a prominent part of health professional training at tertiary institutions. In many instances re-training via short courses or workshops would be the preferred option.

The last recommendation is that nutritionists and dieticians in African countries should be enabled take leading roles in coordinating all efforts to implement appropriate interventions to improve the nutritional status of populations and to prevent future CVD epidemics.

\section{REFERENCES}

I. Lopez AD, Mathers CD, Ezzati M, et al. Global and regional burden of disease and risk factors, 200I: systematic analysis of population health data. Lancet 2006;367: 1747-1757.

2. World Health Organisation (WHO). The World Health Report 2002-reducing risks, promoting healthy life. WHO, Geneva: 2002.

3. Murray C, Lopez A. The Global burden of disease. Washington, DC, World Bank. 1996.

4. Reddy KS, Yusuf S. Emerging epidemic of cardiovascular disease in developing countries. Circulation 1998;97:596-601.

5. World Health Organisation (WHO). The World Health Report 1999 - Making a difference. WHO, Geneva: 1999.

6. Lodenyo HA, McLigeyo SO, Ogola EN. Cardiovascular disease in elderly inpatients at Kenyatta national hospital, Nairobi Kenya. East Afr Med J 1997;74: 647-51.

7. Mbanya JC, Minkoulou J, Salah J, et al. 1998. The prevalence of hypertension in rural and urban Cameroon. Int J Epidemiol 1998;27(2): 18|-5.

8. Kotto RM, Bouelet BA. Cardiovascular diseases in adults in Douala (Cameroon). Cardiologie Tropicale 2000;26(103):61-64.

9. Amoah ADB. Spectrum of Cardiovascular disorders in a national referral centre, Ghana. East Afri Med J 2000;73:215-17.

10. Sarti C, Rastenyte D, Cepaitis Z, Tuomilehto J. International Trends in Mortality From Stroke, 1968 to 1994. Stroke 2000;31:1588.

I I. Ghanem H, Fredj H. Eating habits and cardiovascular risk factors. Press Medicale 1999;28(19): 1005-8.

12. Sliwa K, Wilkinson D, Hansen C, et al. Spectrum of heart disease and risk factors in a black urban population in South Africa (the Heart of Soweto Study): a cohort study. Lancet 2008;37I (9616):915-922.

13. Gillum RF, Blackburn H, Feinleib M. Current strategies for explaining the decline in ischemic heart disease mortality. J Chron Dis 1982;35:467-74.

14. Pisa Z, Uemura K. Trends of mortality from ischemic heart disease and other cardiovascular diseases in 27 countries, 1968-1977. World Health Stat Q 1982; 35.

15. Marmot MG, Booth M, Beral V. Changes in heart disease mortality in England and Wales and other countries. Health Trends 1981;13:33-8.

16. Dobson AJ, Gibberd RW, Wheeler DJ, et al. Age specific trends in mortality from ischaemic heart disease and cerebrovascular disease in Australia. Am J Epidemiology 1981;1 13:407-12.

17. Salonen JT, Puska P, Kottke TS, et al. Decline in mortality from coronary heart disease in Finland from 1969-1979. Brit Med J 1983;286:1857-60.

18. Caterina RD, Zampolli A, Turco SD, et al. Nutritional mechanisms that influence cardiovascular disease. Am J Clin Nutr 2006;83(2):42 I S-426S.

19. Van Horn L, McCoin M, Kris-etherton PM, et al. The evidence for dietary prevention and treatment of cardiovascular disease. I Am Diet Assoc 2008; 108:287-331.

20. Mente A, De Koning L, Shannon HS, Anand SS. A systematic review of the evidence supporting a causal link between dietary factors and coronary heart disease. Arch Intern Med 2009; 169 (7):659-669.

21 . Summary statement of the international expert meeting on the health significance of fat quality of the diet. Cape Town, South Africa, 2009.

22. Reusser ME, Dirienzo DB, Miller GD, et al. Adequate nutrient intake can reduce cardiovascular disease risk in African Americans. J Nat Med Assoc 2003;95(3): 188-194. 
23. American Heart Association Nutrition Committee, Lichtenstein AH, Appel L, et al. Diet and lifestyle recommendations revision 2006: a scientific statement from the American Heart Association Nutrition Committee. Circulation 2006; | |4(1):82-96.

24. Pyörälä K, De Backer G, Graham I, et al. Prevention of coronary heart disease in clinical practice: recommendations of the task force of the European Society of Cardiology, European Atherosclerosis Society and European Society of Hypertension. Atherosclerosis 1994;1 10(2):121-161.

25. Pyörälä K, De Backer G, Graham I, et al. Prevention of coronary heart disease in clinical practice: recommendations of the task force of the European Society of Cardiology, European Atherosclerosis Society and European Society of Hypertension. Eur Heart J 1994; I ( (10): I 300- I331.

26. Mensink RP, Katan MB. Effect of dietary trans fatty acids on high-density and low-density lipoprotein cholesterol levels in healthy subjects. N Engl J Med 1990;323(7):439-445.

27. Howard BV, Van Horn L, Hsia J, et al. Low-fat dietary pattern and risk of cardiovascular disease: the Women's Health Initiative Randomised Controlled Dietary Modification Trial. JAMA 2006;295(6):655-666

28. Oh K, Hu FB, Manson JE, et al. Dietary fat intake and risk of coronary heart disease in women: 20 years of follow-up of the Nurses' Health Study. Am J Epidemiol 2005; 161 ( (7):672-679

29. Ascherio A, Rimm EB, Giovannucci EL, et al. Dietary fat and risk of coronary heart disease in men: cohort follow up study in the United States. BM] 1996;313(7049):84-90.

30. Pietinen $\mathrm{P}$, Ascherio $\mathrm{A}$, Korhonen $\mathrm{P}$, et al. Intake of fatty acids and risk of coronary heart disease in a cohort of Finnish men: the Alpha-Tocopherol, Beta-Carotene Cancer Prevention Study. Am J Epidemiol 1997; 145(10):876-887.

31. Hu FB, Stampfer MJ, Manson JE, et al. Dietary fat intake and the risk of coronary heart disease in women. N Engl J Med 1997;337(21): 1491 - 499.

32. Oomen CM, Ocke MC, Feskens EJ, et al. Association between trans fatty acid intake and 10-year risk of coronary heart disease in the Zutphen Elderly Study: a prospective population-based study. Lancet 200 I;357(9258):746-75 I.

33. Charlton KE, Jooste PL. Eat salt sparingly-sprinkle, don't shake. S Afr J Clin Nutr 200 I; 1 4(3):S55-S63.

34. Di Castelnuovo A, Rotondo S, lacoviello L, et al. Meta-analysis of wine and beer consumption in relation to vascular risk. Circulation 2002; 105:2836-2844.

35. Gronbaek M, Deis A, Sorensen TI, et al. Mortality associated with moderate intakes of wine, beer, or spirits. BMJ 1995;310:1 165-1169.

36. Liu S, Willet WC, Stampfer MJ, et al. A prospective study of dietary glycaemic load, carbohydrate intake, and risk of coronary heart disease in US women. Am j Clin Nutr 2000;7|:|455-|46|.

37. Williamson G. Protective effects of fruit and vegetables in the diet. Nutrition and food Science 1996; 1:6-10.

38. Protein and amino acid requirements inhuman nutrition. Report of a Joint WHO/FAO/UNU Expert Consultation. Geneva, World Health Organisation, 2003 (in press)

39. Fats and oils in human nutrition. Report of a Joint FAO/WHO Expert Consultation. Rome, Food and Agriculture Organisation of the United Nations, 1994 (FAO Food and Nutrition Paper, No. 57).

40. World Health Organisation (WHO). Diet, Nutrition and Prevention of Chronic Diseases, Technical Report Series No. 797. WHO, Geneva. 1990.
41. Hu FB, Stampfer MJ, Rimm EB, et al. A prospective study of egg consumption and risk of cardiovascular disease in men and women. JAMA 1999;281(15): | 387-1394.

42. Geppert J, Kraft V, Demmelmair $H$, et al. Microalgal docosahexaenoic acid decreases plasma triacylglycerol in normolipidaemic vegetarians: A randomised trial. Br J Nutr 2006;95:779-786

43. Sanders TA, Gleason K, Griffin B, et al. Influence of an algal triacylglycerol containing docosahexaenoic acid (22:6n-3) and docosapentaenoic acid (22:5n-6) on cardiovascular risk factors in healthy men and women. Br J Nutr 2006;95: 525-531.

44. Goyens PL, Mensink RP. Effects of alpha-linolenic acid versus those of EPA/ DHA on cardiovascular risk markers in healthy elderly subjects. Eur J Clin Nutr 2006;60:978-984

45. Harper CR, Edwards MC, Jacobson TA. Flaxseed oil supplementation does not affect plasma lipoprotein concentration or particle size in human subjects. J Nutr 2006; 1 36:2844-2848.

46. Zibaeenezhad MJ, Shamsnia SJ, Khorasani M. Walnut consumption in hyperlipidemic patients. Angiology 2005;56:581-583.

47. Zhao G, Etherton TD, Martin KR, et al. Dietary alpha-linolenic acid reduces inflammatory and lipid cardiovascular risk factors in hypercholesterolemic men and women. J Nutr 2004; 134:2991-2997.

48. Tapsell LC, Gillen LG, Patch CS, et al. Including walnuts in a low-fat/modifiedfat diet improves HDL cholesterol-to-total cholesterol ratios in patients with type 2 diabetes. Diabetes Care 2004;27:2777-2783.

49. Rimm EB, Willett WC, Hu FB, et al. Folate and vitamin B-6 from diet and supplements in relation to risk of coronary heart disease among women. JAMA 1998:279:359-364.

50. Hu FB, Stampfer MJ, Manson JE, et al. Dietary intake of alpha-linolenic acid and risk of fatal ischemic heart disease among women. Am J Clin Nutr 1999;69:890-897.

51. Lichtenstein AH, Matthan NR, Jalbert SM, et al. Novel soybean oils with different fatty acid profiles alter cardiovascular disease risk factors in moderately hyperlipidemic subjects. Am J Clin Nutr 2006;84:497-504.

52. Christiansen LI, Lahteenmaki PL, Mannelin MR, et al. Cholesterol-lowering effect of spreads enriched with microcrystalline plant sterols in hypercholesterolemic subjects. Eur J Nutr 200 I;40:66-73.

53. Tikkanen MJ, Hogstrom P, Tuomilehto J, et al. Effect of a diet based on low-fat foods enriched with nonesterified plant sterols and mineral nutrients on serum cholesterol. Am J Cardiol 200 1;88:1 157-1 I 62.

54. Volpe R, Niittynen L, Korpela R, et al. Effects of yoghurt enriched with plant sterols on serum lipids in patients with moderate hypercholesterolaemia. $\mathrm{Br}$ Nutr 2001;86:233-239.

55. Raben A, Vasilaras TH, Moller AC, et al. Sucrose compared with artificia sweeteners: different effects on ad libitum food intake and body weight after 10 week of supplementation in overweight subjects. Am J Clin Nutr 2002; 76(4):721-729

56. Carbohydrates in human nutrition. Report of a Joint FAO/WHO Expert Consultation. Rome, Food and Agriculture Organisation of the United Nations, 1998 (FAO Food and Nutrition Paper, No. 66).

57. Davy BM, Davy KP, Ho RC, et al. High-fiber oat cereal compared with wheat cereal consumption favourably alters LDL-cholesterol subclass and particle numbers in middle-aged and older men. Am J Clin Nutr 2002;76:35I-358. 
58. Van Horn L, Liu K, Gerber J, et al. Oats and soy in lipid-lowering diets for women with hypercholesterolemia: is there synergy? J Am Diet Assoc 2001; 101:1319-1325.

59. Erkkila AT, Herrington DM, Mozaffarian D, et al. Cereal fiber and whole-grain intake are associated with reduced progression of coronary-artery atherosclerosis in postmenopausal women with coronary artery disease. Am Heart J 2005; I50: 94-101.

60. Lairon D, Arnault N, Bertrais S, et al. Dietary fiber intake and risk factors for cardiovascular disease in French adults. Am J Clin Nutr 2005;82:I I 85- I 194.

61. Joint WHO/FAO Expert Consultation. WHO Technical Report Series 916: Diet, Nutrition and the Prevention of Chronic Diseases. 2003. World Health Organisation. Geneva, 2003.

62. Steyn K, Fourie J. eds BRISK study Methodology: Coronary Heart Disease Risk Factor Study in African Population of the Cape Peninsula. MRC Technical Report I. Cape Town: South African Medical Research Council. 1991.

63. Agarwal DP. Cardioprotective effects of light to moderate consumption of alcohol: A review of putative mechanisms. Alcohol 2002;37(5):409-4I5.

64. PT Pisa, A Kruger, HH Vorster, et al. Alcohol consumption and cardiovascular disease risk in an African population in transition: The PURE study. S Afri J Clin Nutr 2000;23(3):S29-S37.

65. Vorster $\mathrm{HH}$. The emergence of cardiovascular disease during urbanisation of Africans. Public Health Nutr 2002;5:269-73.

66. Popkin BM. An overview of the nutrition transition and its implications: the Bellagio meeting. Public Health Nutr 2002;5:93-103.

67. Bradshaw D, Groenewald P, Laubscher R, et al. Initial burden of disease estimates for South Africa 2000. S Afr Med J 2003;93:682-688.

68. Popkin BM, Gordon-Larsen P. The nutrition transition: worldwide obesity dynamics and their determinants. Int J Obesity 2004;28:S2-S9.

69. International Obesity Task Force. Sydney Principles. Guiding principals for reducing the commercial promotion of foods and beverages to children "the Sydney principles", 2007.

70. Vorster $\mathrm{HH}$, Kruger A. Poverty, malnutrition, underdevelopment and cardiovascular disease: a South African perspective. CVJ 2007; 18(5):321-4.

7I. World Health Organisation (WHO). Food based dietary guidelines. WHO/FAO Joint Expect Consultation. Geneva: WHO, 1996

72. World Health Organisation (WHO). Outline of procedural manual for the development and implementation of regional and country-specific food-based dietary guidelines. WHO, Geneva: 2010 (In press).

73. South African Food Based Dietary Guidelines. ed Vorster HH. S Afr J Clin Nutr $2001 ; \mid 4(3): S I-80$

74. Pestana JA, Steyn K, Leiman A, et al. The direct and indirect costs of cardiovascular disease in South Africa in 1991. S Afr Med J 1996;86:679-684.

75. Gazanio TA. Cardiovascular disease in the developing world and its cost effective management. Circulation 2005; I 1 2:3547-3553. 